Check for updates

Cite this: Mol. Omics, 2021 17,472

DOI: $10.1039 / \mathrm{d} 1 \mathrm{mog} 0009 a$

rsc.li/molomics

\section{Correction: Examination of oestrus-dependent alterations of bovine cervico-vaginal mucus glycosylation for potential as optimum fertilisation indicators}

\author{
Marie Le Berre, ${ }^{a b}$ Jared Q. Gerlach, ${ }^{\text {ab }}$ Catherine Loughrey, ${ }^{a b}$ Aileen Creavin, ${ }^{\text {ab }}$ \\ Katarzyna Pluta, ${ }^{\mathrm{C}}$ Mary Gallagher, ${ }^{\mathrm{C}}$ Stephen D. Carrington, ${ }^{\mathrm{C}}$ Lokesh Joshi*ab and \\ Michelle Kilcoyne*bd
}

Correction for 'Examination of oestrus-dependent alterations of bovine cervico-vaginal mucus glycosylation for potential as optimum fertilisation indicators' by Marie Le Berre et al., Mol. Omics, 2021, 17, 338-346, DOI: 10.1039/DOMO00193G.

The authors regret that there was an error in the funding information. "This project was supported by funding from Science Foundation Ireland for a Technology Innovation Development Award (TIDA) Feasibility Award (grant no. 11/TIDA/B2012) and the Centre for Research in Medical Devices (Curam) (grant no. 13/RC/2073). MK acknowledges the Royal Society of Chemistry Analytical Chemistry Trust Fund (ACTF) for an ACTF Fellowship. JQG acknowledges support from Health Research Board Ireland (grant no. HRA_HSR/2010/63). LJ was supported by the SFI Stokes Professor for Glycosciences (grant no. 07/SK/B1250)." should be replaced by "This project was supported by funding from Science Foundation Ireland (SFI) for a Technology Innovation Development Award (TIDA) Feasibility Award (grant no. 11/TIDA/B2012). MK acknowledges the Royal Society of Chemistry Analytical Chemistry Trust Fund (ACTF) for an ACTF Fellowship. JQG acknowledges support from Health Research Board Ireland (grant no. HRA_HSR/2010/63). LJ was supported by the SFI Stokes Professor for Glycosciences (grant no. 07/SK/B1250)."

The Royal Society of Chemistry apologises for these errors and any consequent inconvenience to authors and readers.

\footnotetext{
${ }^{a}$ Glycoscience Group, School of Natural Sciences, National University of Ireland Galway, Galway, Ireland. E-mail: lokesh.joshi@nuigalway.ie

${ }^{b}$ Advanced Glycoscience Research Cluster, School of Natural Sciences, National University of Ireland Galway, Galway, Ireland. E-mail: michelle.kilcoyne@nuigalway.ie

${ }^{c}$ Veterinary Sciences Centre, UCD School of Veterinary Medicine, University College Dublin, Dublin, Ireland

${ }^{d}$ Carbohydrate Signalling Group, Discipline of Microbiology, National University of Ireland Galway, Galway, Ireland
} 